\title{
Identification of quantitative trait loci associated with canopy temperature in soybean
}

\begin{abstract}
Sumandeep K. Bazzer \& Larry C. Purcell ${ }^{\bowtie}$
A consistent risk for soybean (Glycine max L.) production is the impact of drought on growth and yield. Canopy temperature (CT) is an indirect measure of transpiration rate and stomatal conductance and may be valuable in distinguishing differences among genotypes in response to drought. The objective of this study was to map quantitative trait loci (OTLs) associated with CT using thermal infrared imaging in a population of recombinant inbred lines developed from a cross between KS4895 and Jackson. Heritability of CT was $35 \%$ when estimated across environments. QTL analysis identified 11 loci for CT distributed on eight chromosomes that individually explained between 4.6 and $12.3 \%$ of the phenotypic variation. The locus on $\mathrm{Gm} 11$ was identified in two individual environments and across environments and explained the highest proportion of phenotypic variation ( $9.3 \%$ to $11.5 \%)$ in CT. Several of these CT loci coincided with the genomic regions from previous studies associated with canopy wilting, canopy temperature, water use efficiency, and other morpho-physiological traits related with drought tolerance. Candidate genes with biological function related to transpiration, root development, and signal transduction underlie these putative CT loci. These genomic regions may be important resources in soybean breeding programs to improve tolerance to drought.
\end{abstract}

Soybean (Glycine max (L.) Merr.) is one of the most important crops grown in the US on an area of 30.8 million hectares with a production of 96.8 million metric tons and that contributes around $28 \%$ to global production (www.soystats.com). The sustainability of soybean production is threatened by climate changes such as increased temperature, erratic precipitation, and variable weather patterns. Among these factors, drought is one of the major constraints limiting yield potential in legumes and other cereal crops $\mathrm{s}^{1-5}$. Various field studies had reported that drought stress leads to the reduction of 5 to $50 \%$ of soybean yield ${ }^{6,7}$. Thus, there is need for development of cultivars with drought tolerance to cope with adverse climatic conditions and to improve crop performance. Selection for high yield is difficult under drought stress conditions due to its quantitative nature and because of a high interaction of genotype with the environment ${ }^{8}$. Therefore, it is important to identify specific physiological traits that may improve the crop performance and yield under water deficit conditions.

Canopy temperature can be used as surrogate measurement of plant water balance/relations and is an important physiological trait associated with drought tolerance ${ }^{9-15}$. Canopy temperature is closely associated with transpiration rate and stomatal conductance in many crops ${ }^{13,16}$. Due to evaporative cooling, transpiration is negatively correlated with canopy temperature ${ }^{17}$. Under optimum moisture conditions, increased vapor pressure deficit increases evaporative demand resulting in higher transpiration rate and a decrease in canopy temperature provided that stomatal conductance does not change. However, decreased transpiration rate and stomatal conductance under water deficit conditions limits evaporative cooling and leads to increased canopy temperature ${ }^{18-20}$. The genotypes with a cooler canopy under water deficit condition continue transpiration at a relatively high rate, presumably due to a larger store of soil available water compared to genotypes with higher canopy temperature ${ }^{21-23}$.

In bread wheat (Triticum aestivum) and durum wheat (Triticum durum), there is a significant correlation between cooler canopy temperature high yield ${ }^{15,24,25}$. Likewise, there were significant genetic gains in wheat yield when direct selection was made based on a cooler canopy ${ }^{23,26,27}$. A significant correlation between canopy temperature and transpiration was found in sugar beet (Beta vulgaris), rice (Oryza sativa), and potatoes (Solanum tuberosum $)^{28}$. Cooler canopy (or canopy temperature depression) was positively correlated with grain yield in rice $^{29}$, sugarcane (Saccharum officinarum) ${ }^{10,30}$, and chickpea (Cicer arietinum) ${ }^{31,32}$, pearl millet (Penniserum americanum $)^{33}$, and soybean ${ }^{34}$ under water deficit conditions. Canopy temperature depression (CTD) is defined as deviation of plant canopy temperature from the air temperature. Bai and Purcell ${ }^{9}$ found that slow wilting

Department of Crop, Soil, and Environmental Sciences, University of Arkansas, Fayetteville, AR 72704, USA. ${ }^{\boxplus}$ email: Ipurcell@uark.edu 


\begin{tabular}{|l|l|l|l|l|l|l|l|c|}
\hline Env. & Planting date & CT recording date & MaxT $\left({ }^{\circ} \mathbf{C}\right)$ & MinT $\left({ }^{\circ} \mathbf{C}\right)$ & No. of days & VPD $(\mathbf{k P a})$ & $\begin{array}{l}\text { Soil moist. deficit } \\
(\mathbf{m m})\end{array}$ & $\mathbf{h}^{\mathbf{2 b}}(\mathbf{\%})$ \\
\hline PT17 & 9 June 2017 & 25 Aug 2017 & 29 & 15 & 8 & 2.3 & 49 & 9 \\
\hline RH17 & 8 June 2017 & 21 July 2017 & 34 & 25 & 4 & 2.3 & 50 & 22 \\
\hline PT18 & 7 June 2018 & 25 July 2018 & 33 & 19 & 8 & 2.9 & $>75$ & 11 \\
\hline RH18 & 31 May 2018 & 19 July 2018 & 31 & 24 & 11 & 1.6 & 71 & 7 \\
\hline PT19 & 31 May 2019 & 10 Sept 2019 & 37 & 22 & 13 & 3.5 & $>75$ & 51 \\
\hline RH19 & 12 June 2019 & 9 Sept 2019 & 36 & 21 & 13 & 3.3 & $>75$ & 62 \\
\hline AE $^{\text {a }}$ & - & - & 33 & 21 & 57 & 2.6 & 66 & 35 \\
\hline
\end{tabular}

Table 1. Planting date and weather data including maximum temperature (MaxT), minimum temperature (MinT), No. of days without rainfall, estimated vapor pressure deficit (VPD), and estimated soil moisture deficit at the time of canopy temperature measurements for the field experiments conducted at Pine Tree (PT) and Rohwer (RH) in 2017, 2018, and 2019. ${ }^{a} \mathrm{AE}$ denote averaged across environments. ${ }^{\mathrm{b}} \mathrm{h}^{2}$ narrow sense heritability.

soybean genotypes under drought had a cooler canopy than fast wilting genotypes and that a cooler canopy was positively associated with grain yield.

Manual phenotyping/measurement of transpiration and stomatal conductance to detect canopy temperatures differences is difficult and tedious. Therefore, selection criteria for genotypes with cooler canopy must be rapid, relatively simple, and allow the screening of large number of field plots in a short period of time $\mathrm{e}^{35,36}$. The advent of high throughput phenotyping platforms has led to rapid, accurate, and non-destructive monitoring of whole-plant responses and differences in stomatal behavior to water stress ${ }^{37-40}$. Unmanned aerial systems (UAS) provide an efficient phenotyping platform to evaluate a large number of experimental fields for precise, quantitative assessment of CT in segregating mapping populations, and allowing a comparison among genotypes for CT differences ${ }^{13}$. Thermal infrared imaging from a UAS has become an important tool in early growth stages to detect drought stress, improve water use efficiency (WUE), and precisely manage irrigation ${ }^{12,41-44}$.

Combining thermal infrared imaging with genetic mapping may help in understanding the genetic architecture of drought tolerance ${ }^{45-49}$. Mapping studies for CT have been reported in wheat ${ }^{16}$, rice $^{50}$, and maize (Zea mays $)^{51}$. In soybean, genome wide association studies (GWAS) and linkage mapping studies have dissected the genetic basic of several morpho-physiological traits such as canopy wilting ${ }^{52-56}$, carbon isotope ratio $\left(\delta^{13} \mathrm{C}\right)^{57-60}$, oxygen isotope ratio $\left(\delta^{15} \mathrm{O}\right)^{60}$, and canopy coverage ${ }^{61}$. The first GWAS analysis for CT in soybean was conducted using a diverse panel of 345 maturity group IV accessions ${ }^{14}$. Association analysis identified 34 loci associated with CT. However, to date, there has been no report of linkage mapping using thermal infrared imaging to study the genetic basis of CT in soybean.

Thus, the present study aimed to identify the genomic regions associated with CT using a mapping population of 168 recombinant inbred lines (RILs) developed from a cross between KS4895 and Jackson. The objectives of this study were to (1) identify QTLs associated with CT (2) confirm identified CT QTLs with previously mapped QTLs associated with drought tolerance; and (3) search for putative candidate genes underlying these QTLs.

\section{Materials and methods}

One hundred and sixty-eight $\mathrm{F}_{5}$-derived recombinant inbred lines (RILs) generated from a cross between KS4895 (PI 595081) ${ }^{62}$ and Jackson (PI 548657) ${ }^{63}$ were used to identify genomic regions associated with CT. KS4895 is a maturity group (MG) IV cultivar developed by the Kansas Agricultural Experiment Station, and Jackson is a MG VII cultivar developed by the North Carolina Agricultural Experiment Station and the USDA-ARS. These two genotypes were selected as parents because previous research reported that Jackson was more tolerant than KS4895 with regards to $\mathrm{N}_{2}$ fixation response to drought ${ }^{64,65}$. Populations developed from a cross of KS4895 and Jackson were used to study genetic control of traits associated with $\mathrm{N}_{2}$ fixation ${ }^{66}$, canopy wilting ${ }^{54,55}$ and $\delta^{13} \mathrm{C}^{58}$.

The RIL population along with parents were evaluated for CT at the Pine Tree Research Station, $\mathrm{AR}\left(35.11^{\circ} \mathrm{N}\right.$, $90.91^{\circ} \mathrm{W}$ ) on a Calloway silt loam soil (fine, montmorillonitic, thermic Typic Albaqualfs) and Rohwer Research Station, $\operatorname{AR}\left(33.80^{\circ} \mathrm{N}, 91.28^{\circ} \mathrm{W}\right)$ on a Sharkey silty clay soil (very-fine, smectitic, thermic Chromic Epiaquerts) in three consecutive years (2017-2019). Each location by year combination was treated as an individual environment and designated as PT17 (Pine Tree 2017), RH17 (Rohwer 2017), PT18 (Pine Tree 2018), RH18 (Rohwer 2018), PT19 (Pine Tree 2019), and RH19 (Rohwer 2019). A randomized complete block experimental design with two replications was employed at each environment. The details of planting date, CT measurement date, and weather data on the CT measurement day are presented in Table 1. The RILs were planted in nine-row plots that were $4.0-4.5 \mathrm{~m}$ long with $0.15-0.18 \mathrm{~m}$ spacing between rows. The average minimum temperature, maximum temperature, and rainfall for Pine Tree and Rohwer in 2017, 2018, and 2019 were collected from the Southern Regional Climate Center (www.srcc.lsu.edu/station_search) using the Climate Data Portal. An irrigation scheduling program ${ }^{67}$ was used to estimate soil moisture deficit. Vapor pressure deficit (VPD) for each environment was estimated from daily maximum and minimum temperatures, assuming that water vapor pressure was saturated at the minimum temperature ${ }^{68,69}$. The experiments were rainfed for all environments, and experimental fields were managed using recommended practices. 
Phenotypic evaluation. CT measurements were made multiple times (two to five times) in all environments between 1200 and $1400 \mathrm{~h}$ when the sun was unobstructed by clouds. All measurement dates occurred once the canopy was completely closed to avoid the CT measurements being overwhelmed by the heat signature from the soil that occurred prior to canopy closure. Dates for CT measurement were targeted when the estimated soil moisture deficit was $>45 \mathrm{~mm}^{67}$ and soybean development was between full bloom and beginning seedfill ${ }^{9,14}$. Data ultimately used for QTL analysis for each environment were chosen for those dates in which the estimated soil moisture deficit was the greatest as previous research had determined that genotypic differences in CT were not apparent under water replete conditions ${ }^{9}$.

Canopy temperature was determined by using aerial infrared image analysis. A drone (DJI Phantom 4 Pro, www.dji.com/phantom-4-pro) equipped with an infrared (IR) camera (Model: FLIR Tau 2, www.flir.com) with a sensor size of $640 \times 512$ pixels, $25 \mathrm{~mm}$ focal length, sensitivity of $0.05^{\circ} \mathrm{C}$, and an accuracy of $\pm 5 \%$, was flown at a height of $120 \mathrm{~m}$ above the ground at full canopy coverage. A digital video recorder recorded the video stream from the camera. The IR camera is not calibrated. That is, values of CT from the IR range from 0 (cool) to 255 (hot) and cover a range of $12.5^{\circ} \mathrm{C}$, but the specific temperature of the canopy is not determined. Herein, we report values directly from the IR camera as a measure of CT.

The IR images were extracted from the video file using VLC video player (www.videolan.org), and 6 to 17 images representing each plot multiple times were selected manually. Selected IR images were processed using FieldAnalyzer software (www.turfanalyzer.com/field-analyzer) to extract CT values from the average values of 400 to 2000 pixels from the center portion of the IR image of each plot and was used as a measure of CT. There were multiple CT values of each plot extracted from multiple selected images. The final CT values used for analysis was the average CT values determined from analyzing multiple images and after removing values that were more than \pm 2 standard errors from the mean.

Statistical analysis. The phenotypic analysis of CT was performed using SAS v.9.2 software (SAS Institute, 2013). The normality of CT in an individual environment was checked using a Q-Q plot of residuals and the Shapiro-Wilk test ${ }^{70}$. The presence of statistical differences between parents for CT was estimated using a $t$ test. Pearson's correlation analysis between environments and analysis of variance (ANOVA) averaged over environments were performed using PROC CORR $(\alpha=0.05)$ and PROC MIXED procedures, respectively. Heritability was estimated from the variance components calculated with restricted maximum likelihood (REML) method of VARCOMP procedure. Narrow sense heritability $\left(h^{2}\right)$ was calculated using the following formula ${ }^{71}$ :

$$
\begin{gathered}
\text { Across environments: } \mathrm{h}^{2}=\frac{\sigma_{G}^{2}}{\sigma_{G}^{2}+\left(\frac{\sigma_{G E}^{2}}{E}\right)+\left(\frac{\sigma_{e}^{2}}{R E}\right)} \\
\text { Within environments: } \mathrm{h}^{2}=\frac{\sigma_{G}^{2}}{\sigma_{G}^{2}+\left(\frac{\sigma_{e}^{2}}{R}\right)}
\end{gathered}
$$

where $\sigma_{G}^{2}, \sigma_{G E}^{2}, \sigma_{e}^{2}$ are genotypic variance, genotype-by-environment variance, and error variance, respectively, and $E$ and $R$ are the number of environments and replications, respectively. Because $\mathrm{F}_{5}$-derived RILs were used in this research, $\sigma_{G}^{2}$ was composed entirely of additive variance and additive $\times$ additive epistasis variance, with negligible variance associated with other components of dominance variance. As the result, this heritability should be considered as narrow sense heritability. BLUPs (best linear unbiased predictions) were calculated using PROC MIXED procedure for individual environments and averaged across environments, considering all factors in the model as random. Environment was considered a fixed effect in the combined data analysis. QTL analysis of CT was performed using BLUP values to reduce the environmental variations.

QTL analysis. The genetic map for the KS4895 $\times$ Jackson mapping population was previously described by Hwang et al. ${ }^{54}$ and used for QTL analysis in the present study. Briefly, the linkage map consists of 38 simplesequence repeat (SSR) and 510 single-nucleotide polymorphism (SNP) markers with a map size of $2089 \mathrm{cM}$. The list of markers and their physical position on specific chromosomes is provided in Supplementary file 1. The BLUP estimates calculated for individual environments and averaged across environments were used for QTL analysis. The QTL analysis was performed with WinQTL Cartographer v.2.5 $5^{72}$ using composite interval mapping (CIM) and multiple interval mapping (MIM) methods. CIM was performed using Model 6 (standard model) of the Zmapqtl program module ${ }^{73}$. Markers as co-factors to control background noise were selected with forward and backward stepwise regression methods with a walk speed and window size of $1 \mathrm{cM}$. A significant LOD (log of odds) threshold score was determined by a permutation test with 1000 runs and with a genome wide type I error of $5 \%{ }^{74}$. The most likely position of QTLs and an estimate of the magnitude of their additive effects were determined using the CIM method ${ }^{75}$. The confidence interval for putative QTL positions was determined by one-LOD drop on either side of the LOD peak.

Multiple interval mapping (MIM) is a stepwise model procedure ${ }^{76}$ in which presence of significant QTLs and QTL $\times$ QTL interactions are detected using QTLs identified in the CIM method as an initial MIM selection model. This pre-selected MIM model was optimized for identified QTLs, search for new QTLs, and QTL $\times$ QTL interactions by using the 'optimize QTLs positions', 'search for new QTLs', and 'QTL interactions' options, respectively. The MIM model was determined with the minimum Bayesian information criterion (BIC), $c(n)=\operatorname{In}(n)$, and with genome walk speed and window size of $1 \mathrm{cM}$. The criterion used to declare coincident QTLs between 


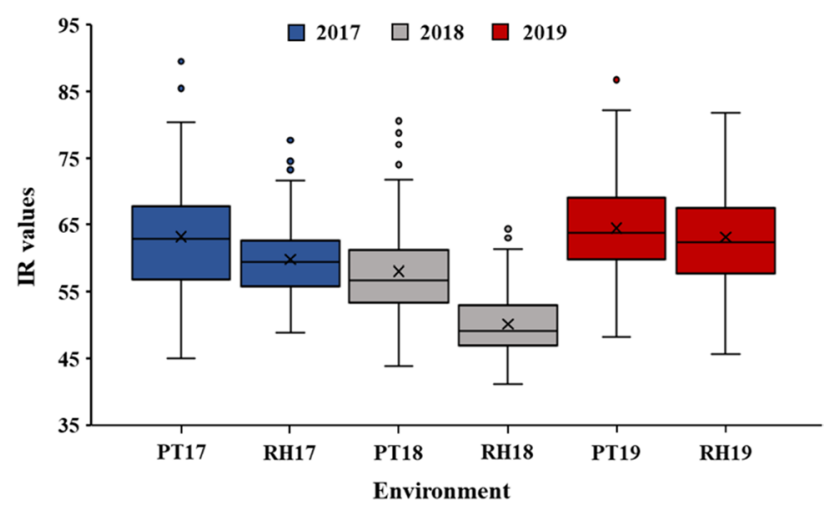

Figure 1. The box plots showed a broad range of canopy temperature in KS4895 $\times$ Jackson RIL population within each environment. Environment prefixes PT and RH denotes Pine Tree and Rohwer, respectively followed by 17 (2017), 18 (2018), and 19 (2019) for years. Box edges represent the upper and lower quartile with a median (bold line in the middle of box) and mean value (cross in the middle of box).

\begin{tabular}{|c|c|c|c|c|c|}
\hline \multirow[b]{2}{*}{ Trait } & \multirow[b]{2}{*}{ Env. $^{\mathrm{a}}$} & \multicolumn{2}{|c|}{ Parental means } & \multicolumn{2}{|c|}{ RILs population } \\
\hline & & \begin{tabular}{|l|} 
KS4895 \\
\end{tabular} & Jackson & Mean & Range $^{c}$ \\
\hline \multirow{7}{*}{$\mathrm{CT}$} & PT17 & $70^{*}$ & 59 & 63 & 45 \\
\hline & RH17 & 57 & 67 & 60 & 29 \\
\hline & PT18 & 71 & 54 & 58 & 37 \\
\hline & RH18 & 59 & 47 & 50 & 24 \\
\hline & PT19 & 71 & 63 & 64 & 39 \\
\hline & RH19 & $86^{*}$ & 53 & 63 & 36 \\
\hline & $\mathrm{AE}^{\mathrm{b}}$ & $69^{*}$ & 57 & 60 & 35 \\
\hline
\end{tabular}

Table 2. A summary statistic of canopy temperature (CT) in the parents (KS4895 and Jackson) and RILs $(n=168)$ population of KS4895 and Jackson evaluated at Pine Tree and Rohwer in 2017, 2018 and 2019.

${ }^{\star}$ Indicated significant difference $(P \leq 0.05)$ between parents. ${ }^{a}$ Environments: Prefixes PT and RH denotes Pine Tree and Rohwer, respectively followed by 17 (2017), 18 (2018), and 19 (2019) for years. ${ }^{b}$ AE denotes averaged across environments. ${ }^{c}$ Range of RIL population is the difference between maximum and minimum IR values.

environments was based on at least a $10 \mathrm{cM}$ overlap in QTL intervals on the linkage map. In this study, a QTL that explained more than $10 \%$ of phenotypic variation was considered a major QTL.

Candidate genes identification. Candidate genes for genomic regions underlying putative QTLs for CT identified in each environment and across environments were searched using the genome browser of Soybase (www.soybase.com). The candidate genes falling within $\pm 1 \mathrm{MB}$ from the nearest marker of putative QTLs were selected according to the Glyma2.0 assembly in Soybase (www.soybase.org) with consideration for those genes having biological function related to transpiration, canopy temperature, rooting, and plant water relations.

\section{Results}

Phenotypic evaluation. On the dates for CT measurement, the maximum temperature ranged from 29 (PT17) to $37^{\circ} \mathrm{C}$ (PT19) and minimum temperature ranged from 15 (PT17) to $25^{\circ} \mathrm{C}$ (RH17) (Table 1 ). The estimated VPD was $\geq 2.3 \mathrm{kPa}$ on day of CT measurements in all environments except for RH18 in which VPD was $1.6 \mathrm{kPa}$. There had been no rainfall from 4 to 13 days prior to CT measurements. The estimated soil moisture deficit ranged from $49 \mathrm{~mm}$ to more than $75 \mathrm{~mm}$ on the day of CT measurements. Irrigation is recommended if estimated soil moisture deficit exceeds $37 \mathrm{~mm}$ for silt loam soils present at Pine Tree and $50 \mathrm{~mm}$ for silty clay soils present at Rohwer ${ }^{67}$, indicating drought-stress conditions on the day of CT measurements.

The CT values had a wide range in all environments with RIL means that ranged from 50 to 64 (Fig. 1, Table 2). Jackson had lower CT values than KS4895 in all environments except RH17 (Table 2), and parents were significantly $(P<0.05)$ different in PT17, RH19, and across environments (AE) (Table 2). Averaged over environments, IR values were 12 units less for Jackson than KS4895, which indicate a CT that was approximately $0.59^{\circ} \mathrm{C}$ cooler for Jackson. The distributions of CT values were approximately normal $(P<0.001)$ except for PT18 and RH18, which were slightly skewed left as indicated by the Shapiro and Wilk test (data not shown, Fig. 1). There were weakly significant correlations for CT between environments for PT17 and PT18 $\left(r=0.18^{\star}\right)$, PT17 and RH19 $\left(r=0.26^{* *}\right)$, RH17 and RH19 $\left(r=0.15^{\star}\right)$, PT19 and RH18 $\left(r=-0.16^{*}\right)$, and PT19 and RH19 $\left(r=0.49^{* * *}\right)$. Across environments, ANOVA indicated that there was a significant effect $(P<0.05)$ of RILs, environment, and 


\begin{tabular}{|c|c|c|c|c|c|c|c|c|c|}
\hline Locus & Chrom. ${ }^{a}$ & Env. ${ }^{b}$ & Position $(\mathbf{b p})^{\mathrm{c}}$ & $\begin{array}{l}\text { Nearest } \\
\text { marker }^{\mathrm{d}}\end{array}$ & $\begin{array}{l}\text { Additive } \\
\text { effect }^{\mathrm{e}}\end{array}$ & $\mathbf{R}^{2 f .}$ & $\begin{array}{l}\text { Favorable } \\
\text { allele }^{\mathrm{g}}\end{array}$ & FM at $95 \% \mathrm{CI}^{\mathrm{h}}$ & Method \\
\hline 1 & Gm02 & PT18 & 2175799 & ss107919808 & -0.27 & 12.3 & KS4895 & $\begin{array}{l}\text { ss107919971- } \\
\text { ss107912545 }\end{array}$ & CIM, MIM \\
\hline 2 & & $\mathrm{AE}$ & 3162143 & ss107912545 & -0.42 & 6.3 & KS4895 & $\begin{array}{l}\text { ss107919808- } \\
\text { ss107913715 }\end{array}$ & CIM, MIM \\
\hline 3 & Gm03 & RH18 & 3847841 & ss107929820 & -0.08 & 6.5 & KS4895 & $\begin{array}{l}\text { ss107913533- } \\
\text { ss107912527 }\end{array}$ & CIM, MIM \\
\hline 4 & Gm10 & PT19 & 2453116 & ss107921662 & 1.19 & 8.5 & Jackson & $\begin{array}{l}\text { ss107921662- } \\
\text { ss107930841 }\end{array}$ & CIM, MIM \\
\hline \multirow{3}{*}{5} & \multirow{3}{*}{ Gm11 } & PT19 & 10350509 & ss107919087 & -1.28 & 11.5 & KS4895 & $\begin{array}{l}\text { ss107919087- } \\
\text { ss107913812 }\end{array}$ & CIM, MIM \\
\hline & & RH19 & 10350509 & ss107919087 & -1.47 & 10.8 & KS4895 & \begin{tabular}{|l|} 
Satt197- \\
ss107927406
\end{tabular} & CIM, MIM \\
\hline & & $\mathrm{AE}$ & 10350509 & ss107919087 & -0.51 & 9.3 & KS4895 & \begin{tabular}{|l|} 
Satt197- \\
ss107927406
\end{tabular} & CIM, MIM \\
\hline 6 & Gm13 & RH18 & 31355907 & ss107912665 & -0.07 & 4.6 & KS4895 & $\begin{array}{l}\text { ss107915606- } \\
\text { ss107912922 }\end{array}$ & MIM \\
\hline 7 & Gm15 & $\mathrm{AE}$ & 51379618 & ss107925861 & -0.42 & 5.4 & KS4895 & $\begin{array}{l}\text { ss107914616- } \\
\text { Sat_376 }\end{array}$ & MIM \\
\hline 8 & Gm16 & PT19 & 26745906 & ss107927055 & 0.65 & 4.9 & Jackson & $\begin{array}{l}\text { ss107927440- } \\
\text { ss107913908 }\end{array}$ & MIM \\
\hline 9 & Gm18 & $\mathrm{AE}$ & 17323638 & ss107921048 & -0.39 & 5.3 & KS4895 & $\begin{array}{l}\text { ss107920369- } \\
\text { ss107914987 }\end{array}$ & CIM \\
\hline \multirow{2}{*}{10} & \multirow{2}{*}{ Gm18 } & RH17 & 50727159 & ss107913405 & -0.27 & 5.7 & KS4895 & \begin{tabular}{|l|} 
ss107919708- \\
ss107921608
\end{tabular} & CIM \\
\hline & & $\mathrm{AE}$ & 50727159 & ss107913405 & -0.40 & 5.4 & KS4895 & \begin{tabular}{|l|} 
ss107919708- \\
ss107913107
\end{tabular} & CIM \\
\hline \multirow{2}{*}{11} & \multirow{2}{*}{ Gm18 } & RH19 & 56161047 & ss107929216 & -1.29 & 8.8 & KS4895 & \begin{tabular}{|l|} 
ss107929175- \\
ss107919550
\end{tabular} & CIM \\
\hline & & $\mathrm{AE}$ & 56161047 & ss107929216 & -0.41 & 6.2 & KS4895 & $\begin{array}{l}\text { ss107929175- } \\
\text { ss107919550 }\end{array}$ & CIM, MIM \\
\hline
\end{tabular}

Table 3. The QTLs associated with canopy temperature identified by composite interval mapping (CIM) and multiple interval mapping (MIM) in a RIL population of KS4895 and Jackson which were evaluated at Pine Tree and Rohwer in 2017, 2018, and 2019. ${ }^{\text {a }}$ Glycine max chromosome on which QTL was present. ${ }^{b}$ Environment in which specific QTL was identified. Prefixes PT and RH denotes Pine Tree and Rohwer, respectively followed by 17 (2017), 18 (2018), and 19 (2019) for years. AE denotes averaged across environments. ${ }^{\mathrm{C}} \mathrm{QTL}$ position in base pairs on respective chromosomes according to Glycine max genome assembly 2.0 (Glyma.Wm82.a2; www.soybase.com). ${ }^{\mathrm{d}}$ Nearest marker to the QTL. ${ }^{\mathrm{e}}$ Additive effect of the QTL. ${ }^{\text {PProportion }(\%)}$ of phenotypic variation explained by specific QTL. ${ }^{\mathrm{g}}$ Allele that decreases CT values was considered as the favorable allele; Positive sign indicates that favorable alleles (decreasing CT) were from Jackson and negative sign indicates the KS4895 allele. ${ }^{\mathrm{h}}$ Flanking markers (FM) present near or at $95 \%$ confidence interval (CI) of the maximum likely QTL positions. The LOD values with \pm 1 declination was used to estimate the $95 \%$ confidence interval.

RILs $\times$ environment interaction on CT, indicating that CT among RILs was affected differently by environmental conditions (data not shown). The narrow sense heritability of CT for individual environments was 9\% (PT17), 11\% (PT18), 51\% (PT19), 22\% (RH17), 7\% (RH18), and 62\% (RH19) and was 35\% when estimated across environments (Table 1).

QTL analysis. Analysis of QTLs associated with CT in individual environments identified seven QTLs present on five chromosomes using the CIM method. Of these seven QTLs, one QTL was identified in RH17, PT18, and RH18 and two QTLs were identified in PT19 and RH19. No QTLs were detected in PT17. These QTLs had additive effects that ranged from -0.08 to -1.17 and explained $5.7 \%$ to $12.3 \%$ of the phenotypic variation (Table 3). The QTLs identified in PT18 (1), PT19 (2), RH18 (1), and RH19 (1) were also identified by the MIM method. Two additional QTLs present on Gm13 (at 31355907 bp) in RH18 and on Gm16 (at 26745906 bp) in PT19 were identified by the MIM method but were not identified by the CIM method (Table 3).

Across environment (AE) QTL analysis of CT identified five QTLs present on Gm02 (1), Gm11 (1), and Gm18 (3) with additive effects ranging from -0.39 to -0.51 and explaining phenotypic variation from 5.3 to 9.3\%. Three out of five AE QTLs were common between CIM and MIM methods, and one new QTL on Gm15 (at 51379618 bp) was identified only by the MIM method (Table 3). The QTL present on Gm11 (at 10350509 bp) was common among PT19, RH19, and AE. The QTL on Gm18 (at 50727159 bp) was identified in RH17 and AE, and the QTL on Gm18 (at 56161047 bp) was common for RH19 and AE. All other QTLs were environmentally specific (Table 3). The favorable alleles for deceasing CT for all the QTLs were from KS4895 except for the QTLs on Gm10 and Gm16. QTL $\times$ QTL interactions were identified between the QTLs present on Gm11 and Gm16 
in PT19 by the MIM method. This interaction explained 5.7\% of the phenotypic variation with the favorable allele contributed by KS4895.

Candidate gene identification. There were more than 1092 candidate genes present within $\pm 1 \mathrm{MB}$ of the nearest markers for putative QTLs with a range from 53 to 206 genes for individual QTLs. A list of these genes (Glyma2.0 ID) with their biological annotation is provided in Supplementary file 2. Out of these 1092 genes, those having biological function related to stomatal complex morphogenesis, regulation of stomatal movement, response to water deprivation, response to abscisic acid (ABA), ABA mediated signaling pathway, ABA transport, root hair elongation, root hair cell differentiation, primary and adventitious root development, root morphogenesis, water transport, response to osmotic and oxidative stress, signal transduction, and response to different hormones stimulus were considered to play a potential role in controlling CT in response to different soil moisture conditions (bold text in Supplementary file 2).

\section{Discussion}

Remote sensing with thermal infrared imagining provides a powerful approach to measure and compare temperature differences of plant canopies of a large number of genotypes for field scale experiments and has been widely used in various crops ${ }^{3,13-15,43,77}$. The present study investigated the genetic control of CT in a population derived from a cross between KS4895 and Jackson, which was evaluated across six environments. Under replete soil moisture and aerial environmental conditions, plants continue to transpire through open stomata. In contrast, as soil moisture becomes limiting, plants close stomata as a preventive mechanism, transpiration decreases, and there is an increase in $\mathrm{CT}^{31}$. Those genotypes that have access to soil moisture continue transpiration during drought stress, resulting in a cooler canopy. High soil moisture deficit and VPD at the time of CT measurements resulted in drought stress in all environments (Table 1). The PT19 and RH19 environments had greater soil moisture deficit and VPD, resulting in greater differences among RILs and higher heritability of CT as compared to other environments.

For all environments there was transgressive segregation among RILs with lower and greater CT than the parents, indicating the distribution of favorable alleles for cooler canopy temperature in both parents. CT is highly influenced by environmental conditions (soil moisture availability, vapor pressure deficit, air temperature) and plant morphology (canopy and root architecture conditions) $)^{34,78}$, resulting in significant genotype $\times$ environment interactions. While the $\mathrm{h}^{2}$ of CT was $35 \%$ when estimated across six environments, and the range of $\mathrm{h}^{2}$ among environments was from 7 to $62 \%$ (Table 1 ). The two environments in which $\mathrm{h}^{2}$ was $>50 \%$ were noted for a severe soil moisture deficit ( $>75 \mathrm{~mm}$ ), maximum temperatures $\geq 36^{\circ} \mathrm{C}$, and VPD $\geq 3.3$ (Table 1). From this it appears that high $\mathrm{h}^{2}$ did not appear to be solely due to soil moisture deficit as PT18 and RH18 had severe soil moisture deficit but had $h^{2} \leq 11 \%$. Environments with high $h^{2}$ (PT19 and RH19) both had severe soil moisture deficit $(\geq 75 \mathrm{~mm})$ combined with high temperature $\left(\geq 36^{\circ} \mathrm{C}\right)$ and high VPD $(\geq 3.3 \mathrm{kPa})$. Along with making measurements when the canopy is completely closed and the sun is completely unobstructed, other conditions for increasing $\mathrm{h}^{2}$ for CT include making measurements when there is a high soil moisture deficit, VPD exceeds $3.3 \mathrm{kPa}$, and when maximum temperatures are high. Additional research is needed in order to define better the conditions that would optimize CT measurements and increase $\mathrm{h}^{2}$. Kaler et al. ${ }^{14}$ reported a broad sense heritability $(\mathrm{H})$ of $19 \%$ for CT in a diverse panel of soybean accessions evaluated in different environments using GWAS. Likewise, low to moderate broad sense heritability of CT/CTD was reported in wheat $(\mathrm{H}=16 \% \text { to } 38 \%)^{79-81}$, in sugarcane $(\mathrm{H}=9 \% \text { to } 44 \%)^{82}$, and in rice $(\mathrm{H}=21 \% \text { to } 30 \%)^{83}$. The low heritability of CT/CTD in soybean and other crops indicate that this trait is highly influenced by environmental conditions ${ }^{84}$.

The complexity of CT in soybean is further indicated by detection of multiple QTLs by CIM and MIM methods. The QTL analysis for CT using CIM and MIM methods identified a total of nine QTLs in individual environments and six QTLs when data were averaged across environments (Table 3). Most of these QTLs were environmentally specific except the QTLs present on Gm11 (at 10350509 bp) and Gm18 (at 50727159 bp and $56161047 \mathrm{bp}$ ), which were common in at least one individual environment and across environments (Table 3). The QTLs present at Locus 5 on Gm11 explained phenotypic variation that ranged from 9.3\% to $11.5 \%$ and is considered a major QTL (Table 3). The markers linked with these QTLs have potential utility using marker assisted selection or genomic selection in a breeding program. The inconsistency of QTLs among environments might be due to different environmental factors such as field moisture status, soil temperature and depth, solar radiation, and VPD. Although QTLs were generally environmentally specific, most of these QTLs were detected by both CIM and MIM methods, which increases the confidence of these results. Of particular interest are environmental conditions that could improve consistency and increase heritability of CT. More research is needed to increase the utility of markers linked with QTLs identified in specific environments in selecting genotypes with a cooler canopy and to determine environmental conditions that optimize heritability.

Considering the overlapping confidence interval of QTLs identified in individual environments and across environments, we found 11 loci on eight chromosomes (Table 3, Fig. 2). The flanking markers position of each loci is provided in the Supplementary file 3. Even though Jackson tended to have lower CT among environments (Table 2), there were nine favorable loci from KS4895 and two favorable loci from Jackson. Hwang et al. ${ }^{54}$ found that KS4895 contributed many of the favorable alleles for slow canopy wilting that were identified in multiple biparental populations. Bai and Purcell ${ }^{9}$ found a positive correlation $(0.37<r<0.62)$ between cooler CT and slow canopy wilting. There is a possibility that KS4895 has both slow canopy wilting and cooler canopy temperature alleles in the KS4895 $\times$ Jackson population.

For comparative analysis of CT loci with QTLs associated with plant water relations and drought tolerance related traits, the putative CT loci were aligned on the soybean linkage map in Soybase (www.soybase.com). The QTLs previously mapped within the 95\% confidence interval of putative QTLs in this study were considered to be 


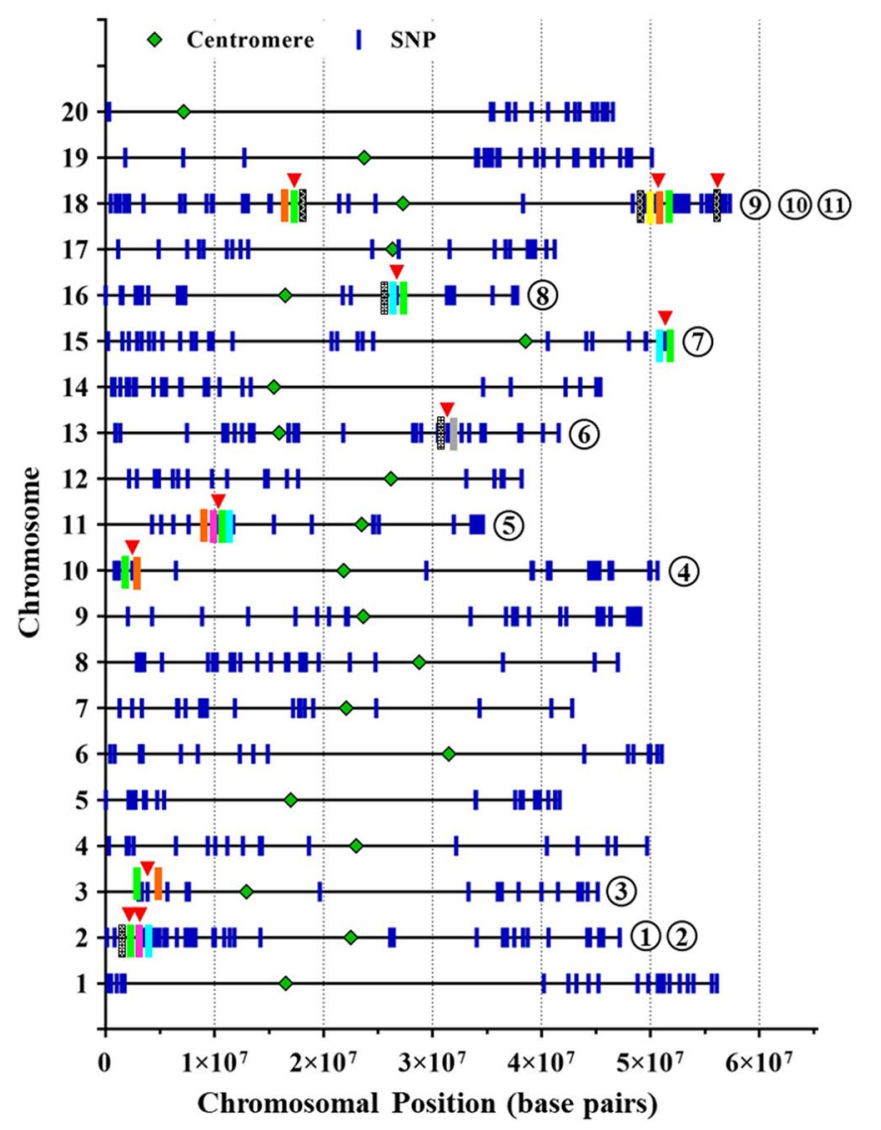

CT Loci

Previously reported QTLs (from Soybase)

CW QTL from GWAS

I CW QTL from Linkage mapping

I CT QTL from GWAS

CC QTL from GWAS

$\delta^{18} \mathrm{O}$ QTL

WUE $/ \delta^{13} \mathrm{C}$ QTL

| Root morphology-related traits QTL

Figure 2. Physical position of SNPs on soybean chromosomes and position of loci (red downward triangle) associated with CT. The numbers in the black circles represent the loci number on a specific chromosome. Vertical colored bars (except blue) indicate the other QTLs found at the same positions in previous studies. CW and CT denote canopy wilting and canopy temperature, respectively.

present in the same genomic regions. The CT Loci 1 and 2 (on Gm02) coincide with a canopy wilting QTL found in a population derived from KS4895 and Jackson (09705KJ population) that is different from the population used in the present research and in a population derived from Benning and PI $416937^{54}$. The favorable alleles for slow canopy wilting at this locus are from KS4895 and PI 416937, consistent with the present research that the KS4895 allele is associated with cool CT. These loci localized in a genomic cluster found in meta-analysis of canopy wilting QTLs using multiple biparental populations ${ }^{55}$. The loci were also mapped in an association panel in the genomic regions associated with canopy wilting ${ }^{56}$, canopy coverage ${ }^{61}$, and $\delta^{13} \mathrm{C}^{60}$. The co-localization of these drought-related QTLs with CT indicates the strong relationship among transpiration, WUE, canopy wilting, and CT.

Locus 3 (on Gm03) and Locus 4 (on Gm10) coincide with QTLs for $\mathrm{CT}^{14}$ and canopy wilting ${ }^{56}$, respectively, that were identified in GWAS. Locus 5 (on Gm11) maps to the same genomic region associated with $\mathrm{CT}^{14}$, canopy wilting $^{56}$, and canopy coverage ${ }^{61}$ identified in GWAS analysis conducted using a diverse panel of soybean accessions. Locus 5 also coincides with a QTL for canopy wilting ${ }^{54}$ and for yield (unpublished results, Bazzer and Purcell) identified in population with KS4895 as a parent; the favorable alleles for slow canopy wilting in both these populations were from KS4895 as they were for CT in the present study.

Locus 6 (on Gm13) overlaps with a QTL for $\delta^{13} \mathrm{C}$ found by GWAS ${ }^{60}$. Nguyen et al.$^{85}$ mapped a QTL for root area and root length at the same genomic location in a population derived from Tachinagaha $\times$ Iyodaizu. Rooting depth and area are drought avoidance mechanisms that may increase water availability ${ }^{86}$. The coincidence of CT and root morphology QTLs may point to a root system that extracts water from deeper soil horizons and results in cooler canopy during drought. In wheat, CT QTLs have been linked with rooting traits that allow extraction of more water from soil under drought ${ }^{87}$.

Locus 7 (on Gm15) and Locus 8 (on Gm16) coincide with canopy wilting ${ }^{56}$ and canopy coverage ${ }^{61}$ that were identified by GWAS. In addition, Locus 8 also overlaps with $\delta^{13} \mathrm{C}^{60}$. Earlier canopy coverage helps to decrease the water loss by soil evaporation relative to transpiration and improve WUE ${ }^{88}$. Locus 9 (on Gm18 at 17323638 bp) coincides with a WUE QTL mapped in a Young $\times$ PI416937 population with the 'Young' allele increasing WUE ${ }^{89}$. Locus 9 and Locus 10 (on Gm18 at 50727159 bp) also fall in the genomic region harboring QTLs for CT ${ }^{14}$, canopy wilting ${ }^{56}$, and $\delta^{13} \mathrm{C}^{59,60}$ identified by GWAS. In addition, Locus 10 overlaps with the oxygen isotope ratio ${ }^{60}$, which is a proxy for measurement of transpiration and is associated with stomatal conductance ${ }^{90}$. 
Locus 11 (on $\mathrm{Gm} 18$ at $56161047 \mathrm{bp}$ ) coincides with $\delta^{13} \mathrm{C}$ identified in the same population as the present research ${ }^{58}$. The favorable allele for $\delta^{13} \mathrm{C}$ at this locus was from Jackson, while KS4895 provided the favorable allele for CT at this locus. The coincidence of $\delta^{13} \mathrm{C}$ and CT QTLs illustrates a shared genetic relationship between these two physiological traits. The co-localization of putative CT loci with QTLs associated with other morphophysiological traits such as WUE, canopy wilting, canopy coverage, and transpiration may be a pleiotropic effect of the same genes controlling these traits or that the genes are spaced closely together on specific chromosomes.

The candidate gene search underlying putative CT loci identified genes with functions related to plant water relations, root morphology, and transpiration. These include genes involved in stomatal complex morphogenesis, regulation of stomatal movement, response to water deprivation, response to abscisic acid (ABA), ABA mediated signaling pathway, $\mathrm{ABA}$ transport, root hair elongation, root hair cell differentiation, response to oxidative stress, and signal transduction.

The upregulation of root morphology (lateral root formation, root hair elongation, root development response to $\mathrm{ABA}$ ) related genes during drought may result in extracting residual soil moisture that maintains primary growth and developmental processes. In wheat, deeper root development in response to drought stress resulted in a cooler canopy and an increase in yield ${ }^{25,91}$. Aquaporin-related genes were also found underlying CT loci and these membrane proteins allow movement of water throughout plant in response to stress ${ }^{92}$. The co-localization of CT loci with QTLs associated with drought tolerance related traits and with underlying candidate genes with biological function related to transpiration, stomatal conductance, and plant water relations increases the probability that putative CT loci are associated with variation in CT in the present research. Additional research is needed to confirm the canopy temperature QTLs in different populations and in different environments to increase the efficiency of these genomic regions in selecting genotypes with a cooler canopy and with drought tolerance.

\section{Conclusions}

In the present study, we identified genomic regions associated with CT in a recombinant inbred population derived from KS4895 and Jackson that was phenotyped in six different environments. These results represent the first QTLs for CT identified in soybean using a biparental population. The population segregated for CT in all environments and was used for QTL analysis. The heritability of CT was relatively low as compared to other morpho-physiological traits due to greater influence of different environmental factors. Eleven genomic loci present on eight chromosomes for CT were identified across several environments. The CT locus present on Gm11 explained phenotypic variation more than $10 \%$ and was considered as a major QTL. The favorable allele for cooler canopy for most of the loci were from KS4895, which were also coincident with canopy wilting QTLs identified in multiple biparental populations by Hwang et al. ${ }^{54}$. The identified CT QTLs coincided with QTLs associated with drought tolerance related traits mapped in previous studies, and genomic regions underlying these putative CT have the genes with biological function related to transpiration, stomatal conductance, and plant water relations. More research is needed to confirm these QTLs in different genetic backgrounds and in multiple/different environments to evaluate the efficiency of these QTLs to use in soybean breeding for selecting genotypes with a cooler canopy and drought tolerance.

Received: 17 July 2020; Accepted: 5 October 2020

Published online: 19 October 2020

\section{References}

1. Daryanto, S., Wang, L. \& Jacinthe, P. Global synthesis of drought effects on maize and wheat production. PLoS ONE https://doi. org/10.1371/journal.pone.0156362 (2016).

2. Harrison, M. T., Tardieu, F., Dong, Z., Messina, C. D. \& Hammer, G. L. Characterizing drought stress and trait influence on maize yield under current and future conditions. Glob. Change Biol. 20, 867-878 (2014).

3. Kashiwagi, J. et al. Scope for improvement of yield under drought through the root traits in chickpea (Cicer arietinum L.). Field Crops Res. 170, 47-54 (2015).

4. Ray, D. K., Mueller, N. D., West, P. C. \& Foley, J. A. Yield trends are insufficient to double global crop production by 2050. PLoS ONE 8, e66428. https://doi.org/10.1371/journalpone0066428 (2013).

5. Specht, J. E., Hume, D. J. \& Kumudini, S. V. Soybean yield potential-a genetic and physiological perspective. Crop Sci. 39, 1560-1570 (1999).

6. Frederick, J. R., Camp, C. R. \& Bauer, P. J. Drought-stress effects on branch and mainstem seed yield and yield components of determinate soybean. Crop Sci. 41, 759-763 (2001).

7. Sadeghipour, O. \& Abbasi, S. Soybean response to drought and seed inoculation. World Appl. Sci. J. 17, 55-60 (2012).

8. Jackson, P., Robertson, M., Cooper, M. \& Hammer, G. The role of physiological understanding in plant breeding; from a breeding perspective. Field Crops Res. 49, 11-37 (1996).

9. Bai, H. \& Purcell, L. C. Aerial canopy temperature differences between fast- and slow-wilting soybean genotypes. J. Agron. Crop Sci. 204, 243-251 (2018)

10. Chapman, S. C. et al. Pheno-copter: a low-altitude, autonomous remote-sensing robotic helicopter for high-throughput field-based phenotyping. Agronomy 4, 279-301 (2014).

11. Cobb, J. N., Declerck, G., Greenberg, A., Clark, R. \& McCouch, S. Next-generation phenotyping: Requirements and strategies for enhancing our understanding of genotype-phenotype relationships and its relevance to crop improvement. Theor. Appl. Genet. 126, 867-887 (2013).

12. Jackson, R. D., Idso, S. B., Reginato, R. J. \& Pinter, P. J. Canopy temperature as a crop water stress indicator. Water Resour. Res. 17, $1133-1138$ (1981).

13. Jones, H. G. et al. Thermal infrared imaging of crop canopies for the remote diagnosis and quantification of plant responses to water stress in the field. Funct. Plant Biol. 36, 978-989 (2009).

14. Kaler, A. S. et al. Association mapping identifies loci for canopy temperature under drought in diverse soybean genotypes. Euphytica 214, 135 (2018).

15. Yousfi, S. et al. Comparative performance of remote sensing methods in assessing wheat performance under Mediterranean conditions. Agric. Water Manag. 164, 137-147 (2016). 
16. Rebetzke, G. J., Rattey, A. R., Farquhar, G. D., Richards, R. A. \& Condon, A. G. Genomic regions for canopy temperature and their genetic association with stomatal conductance and grain yield in wheat. Funct. Plant Biol. 40, 14-33 (2013).

17. Inoue, Y., Kimball, B. A., Jackson, R. D., Pinter, P. J. \& Reginato, R. J. Remote estimation of leaf transpiration rate and stomatal resistance based on infrared thermometry. Agric. For. Meteorol. 51, 21-33 (1990).

18. Gates, D. M. Transpiration and leaf temperature. Annu. Rev. Plant Physiol. 19, 211-238 (1968).

19. Jones, H. Remote detection of crop water stress and distinguishing it from other stresses. Acta Hortic. 922, 23-34 (2010).

20. Tanner, C. B. Plant temperatures. Agron. J. 55, 210-211 (1963).

21. Ludlow, M. M. \& Muchow, R. C. A critical evaluation of traits for improving crop yields in water-limited environments. Adv. Agron. 43, 107-153 (1990).

22. Reynolds, M., Dreccer, F. \& Trethowan, R. Drought-adaptive traits derived from wheat wild relatives and landraces. J. Exp. Bot. 58, 177-186 (2007).

23. Reynolds, M. P., Manes, Y., Izanloo, A. \& Langridge, P. Phenotyping for physiological breeding and gene discovery in wheat. Ann. Appl. Biol. 155, 309-320 (2009).

24. Fischer, R. A. et al. Wheat yield progress associated with higher stomatal conductance and photosynthetic rate, and cooler canopies. Crop Sci. 38, 1467-1475 (1998).

25. Lopes, M. S. \& Reynolds, M. P. Partitioning of assimilates to deeper roots is associated with cooler canopies and increased yield under drought in wheat. Funct. Plant. Biol. 37, 147-156 (2010).

26. Brennan, J. P., Condon, A. G., Van Ginkel, M. \& Reynolds, M. P. An economic assessment of the use of physiological selection for stomatal aperture-related traits in the CIMMYT wheat breeding programme. J. Agric. Sci. 145, 187-194 (2007).

27. Reynolds, M. P., Rajaram, S. \& Sayre, K. D. Physiological and genetic changes of irrigated wheat in the post-green revolution period and approaches for meeting projected global demand. Crop Sci. 39, 1611-1621 (1999).

28. Fukuoka, M. Improvement of a method for measuring canopy temperature in field crops using an infrared thermograph. Dissertation, Hokkaido University, Sapporo, Japan (2005).

29. Prince, S. J., Beena, R., Gomez, S. M., Senthivel, S. \& Babu, R. C. Mapping consistent rice (Oryza sativa L.) yield qtls under drought stress in target rainfed environments. Rice 8, 25 (2015).

30. Basnayake, J., Jackson, P. A., Inman-Bamber, N. G. \& Lakshmanan, P. Sugarcane for water-limited environments: variation in stomatal conductance and its genetic correlation with crop productivity. J. Exp. Bot. 66, 3945-3958 (2015).

31. Kashiwagi, J., Krishnamurthy, L., Upadhyaya, H. D. \& Gaur, P. M. Rapid screening technique for canopy temperature status and its relevance to drought tolerance improvement in chickpea. J. SAT Agric. Res. 6, 105-114 (2008).

32. Purushothaman, R. et al. Association of mid-reproductive stage canopy temperature depression with the molecular markers and grain yields of chickpea (Cicer arietinum L.) germplasm under terminal drought. Field Crops Res. 174, 1-11 (2015).

33. Singh, P. \& Kanemasu, E. T. Leaf and canopy temperatures of pearl millet genotypes under irrigated and nonirrigated conditions. Agron. J. 75, 497-501 (1983).

34. Kumar, M. et al. Canopy temperature depression (CTD) and canopy greenness associated with variation in seed yield of soybean genotypes grown in semi-arid environment. S. Afr. J. Bot. 113, 230-238 (2017).

35. Araus, J. L., Slafer, G. A., Reynolds, M. P. \& Royo, C. Plant breeding and drought in C3 cereals: what should we breed for?. Ann. Bot. 89, 925-940 (2002).

36. Mitra, J. Genetics and genetic improvement of drought resistance in crop plants. Curr. Sci. 80, 758-763 (2001).

37. Berger, B., Parent, B. \& Tester, M. High-throughput shoot imaging to study drought responses. J. Exp. Bot. 61, 3519-3528 (2010).

38. Chen, D. et al. Dissecting the phenotypic components of crop plant growth and drought responses based on high-throughput image analysis. Plant Cell 26, 4636-4655 (2014).

39. Golzarian, M. R. et al. Accurate inference of shoot biomass from high-throughput images of cereal plants. Plant Methods 7, 2 (2011).

40. Honsdorf, N., March, T. J., Berger, B., Tester, M. \& Pillen, K. High throughput phenotyping to detect drought tolerance QTL in wild barley introgression lines. PLoS ONE 9, e97047 (2014).

41. Idso, S. B., Jackson, R. D., Pinter, P. J. Jr., Reginato, R. J. \& Hatfield, J. L. Normalizing the stress-degree-day parameter for environmental variability. Agric. Meteorol. 24, 45-55 (1981).

42. Jackson, R. D., Reginato, R. J. \& Idso, S. B. Wheat canopy temperature: a practical tool for evaluating water requirements. Water Resour. Res. 13, 651-656 (1977).

43. Jones, H. G. Application of thermal imaging and infrared sensing in plant physiology and ecophysiology. Adv. Bot. Res. 41, 107-163 (2004).

44. Mengistu, A., Tachibana, H., Epstein, A. H., Bidne, K. G. \& Hatfield, J. D. Use of leaf temperature to measure the effect of brown stem rot and soil moisture stress and its relation to yields of soybeans. Plant Dis. 71, 632-634 (1987).

45. Bac-Molenaar, J. A., Vreugdenhil, D., Granier, C. \& Keurentjes, J. J. B. Genome-wide association mapping of growth dynamics detects time-specific and general quantitative trait loci. J. Exp. Bot. 66, 5567-5580 (2015).

46. Busemeyer, L. et al. Precision phenotyping of biomass accumulation in triticale reveals temporal genetic patterns of regulation. Sci. Rep. 3, 2442 (2013).

47. Moore, C. R. et al. High-throughput computer vision introduces the time axis to a quantitative trait map of a plant growth response. Genetics 195, 1077-1086 (2013).

48. Slovak, R. et al. A scalable open-source pipeline for large-scale root phenotyping of Arabidopsis. Plant Cell 26, 2390-2403 (2014).

49. Yang, W. et al. Combining high-throughput phenotyping and genome-wide association studies to reveal natural genetic variation in rice. Nat. Commun. 5, 5087 (2014).

50. Liu, H. et al. Correlation analysis and QTL identification for canopy temperature, leaf water potential and spikelet fertility in rice under contrasting moisture regimes. Chin. Sci. Bull. 50, 317-326 (2005).

51. Liu, Y. et al. Maize leaf temperature responses to drought: thermal imaging and quantitative trait loci (QTL) mapping. Environ. Exp. Bot. 71, 158-165 (2011).

52. Abdel-Haleem, H. et al. Mapping of quantitative trait loci for canopy wilting trait in soybean (Glycine max L. Merr). Theor. Appl. Genet. 125, 837-846 (2012).

53. Charlson, D. V. et al. Polygenic inheritance of canopy wilting in soybean [Glycine max (L.) Merr.]. Theor. Appl. Genet. 119, 587-594 (2009).

54. Hwang, S. et al. Confirmation of delayed canopy wilting QTLs from multiple soybean mapping populations. Theor. Appl. Genet. 128, 2047-2065 (2015)

55. Hwang, S. et al. Meta-analysis to refine map position and reduce confidence intervals for delayed canopy wilting QTLs in soybean. Mol. Breed. 36, 91 (2016).

56. Kaler, A. S., Ray, J. D., Schapaugh, W. T., King, C. A. \& Purcell, L. C. Genome-wide association mapping of canopy wilting in diverse soybean genotypes. Theor. Appl. Genet. 130, 2203-2217 (2017).

57. Bazzer, S. K. et al. Identification of quantitative trait loci for carbon isotope ratio $\left(\delta^{13} \mathrm{C}\right)$ in a recombinant inbred population of soybean. Theor. Appl. Genet. 133, 2141-2155 (2020).

58. Bazzer, S. K. et al. Mapping and confirmation of quantitative trait loci (QTLs) associated with carbon isotope ratio $\left(\delta^{13} \mathrm{C}\right)$ in soybean. Crop Sci. https://doi.org/10.1002/csc2.20240 (2020). 
59. Dhanapal, A. P. et al. Genome-wide association study (GWAS) of carbon isotope ratio ( $\delta 13 \mathrm{C})$ in diverse soybean [Glycine max (L.) Merr.] genotypes. Theor. Appl. Genet. 128, 73-91 (2015).

60. Kaler, A. S. et al. Genome-wide association mapping of carbon isotope and oxygen isotope ratios in diverse soybean genotypes. Crop Sci. 57, 3085-3100 (2017).

61. Kaler, A. S. et al. Association mapping identifies loci for canopy coverage in diverse soybean genotypes. Mol. Breed. 38, 50 (2018).

62. Schapaugh, W. T. \& Dille, R. E. Registration of 'KS4895' soybean. Crop Sci. 38, 892 (1998).

63. Johnson, H. W. Registration of soybean varieties VI. J. Agron. 11, 690-691 (1958).

64. King, C. A. \& Purcell, L. C. Genotypic variation for shoot N concentration and response to water deficits in soybean. Crop Sci. 46, 2396-2402 (2006).

65. Purcell, L. C., de Silva, M., King, C. A. \& Kim, W. H. Biomass accumulation and allocation in soybean associated with genotypic differences in tolerance of nitrogen fixation to water deficits. Plant Soil 196, 101-113 (1997).

66. Hwang, S. et al. Genetics and mapping of quantitative traits for nodule number, weight, and size in soybean (Glycine max L. [Merr.]). Euphytica 195, 419-434 (2014).

67. Purcell, L. C., Edwards, J. T. \& Brye, K. R. Soybean yield and biomass responses to cumulative transpiration: questioning widely held beliefs. Field Crop Res. 101, 10-18 (2007).

68. Allen, R. G., Pereira, L. S., Raes, D. \& Smith, M. Crop evapo-transpiration: Guidelines for computing crop water requirements. FAO Irrig. and Drainage Paper 56. FAO, Rome, Italy (1998).

69. Purcell, L. C., Sinclair, T. R. \& McNew, R. W. Drought avoidance assessment for summer annual crops using long-term weather data. Agron. J. 95, 1566-1576 (2003).

70. Shapiro, S. S. \& Wilk, M. B. An analysis of variance test for normality (complete samples). Biometrika 52, 591-611 (1965).

71. Holland, J. B., Nyquist, W. E. \& Cervantes-Martinez, C. T. Estimating and interpreting heritability for plant breeding: an update. Plant Breed. Rev. 22, 9-112 (2003).

72. Wang, S., Basten, C. J. \& Zeng, Z. B. Windows QTL Cartographer 2.5. Department of Statistics, North Carolina State University, Raleigh, North Carolina. (2007).

73. Zeng, Z. B. Precision mapping of quantitative trait loci. Genetics 136, 1457-1468 (1994).

74. Doerge, R. W. \& Churchill, G. A. Permutation tests for multiple loci affecting a quantitative character. Genetics 142, 285-294 (1996).

75. Jansen, R. C. \& Stam, P. High resolution of quantitative traits into multiple loci via interval mapping. Genetics 136, 1447-1455 (1994).

76. Kao, C. H., Zeng, Z. B. \& Teasdale, R. D. Multiple interval mapping for quantitative trait loci. Genetics 152, 1203-1216 (1999).

77. Merlot, S. et al. Use of infrared thermal imaging to isolate Arabidopsis mutants defective in stomatal regulation. Plant J. 30, 601-609 (2002).

78. Hopkins, W. G. Introduction to Plant Physiology 2nd edn. (Wiley, New York, 1999).

79. Gao, F. et al. Genome-wide linkage mapping of QTL for physiological traits in a Chinese wheat population using the 90K SNP array. Euphytica 209, 789-804 (2016).

80. Sukumaran, S., Dreisigacker, S., Lopes, M., Chavez, P. \& Reynolds, M. P. Genome-wide association study for grain yield and related traits in an elite spring wheat population grown in temperate irrigated environments. Theor. Appl. Genet. 128, 353-363 (2015).

81. Tahmasebi, S., Heidari, B., Pakniyat, H. \& McIntyre, C. L. Mapping QTLs associated with agronomic and physiological traits under terminal drought and heat stress conditions in wheat (Triticum aestivum L.). Genome 59, 1-20 (2016).

82. Natarajan, S., Basnayake, J., Wei, X. \& Lakshmanan, P. High-throughput phenotyping of indirect traits for early-stage selection in sugarcane breeding. Remote Sens. 11, 2952 (2019).

83. Saikumar, S. et al. Grain yield responses to varied level of moisture stress at reproductive stage in an interspecific population derived from Swarna/O. glaberrima introgression line. NJAS Wagen J. Life Sci. 78, 111-122 (2016).

84. Ripullone, F. et al. Environmental effects on oxygen isotope enrichment of leaf water in cotton leaves. Plant Physiol. 146, 729-736 (2008).

85. Nguyen, L. V. et al. Mapping quantitative trait loci for root development under hypoxia conditions in soybean (Glycine max L. Merr.). Theor. Appl. Genet. 130, 743-755 (2017).

86. Pantalone, V. R., Rebetzke, G. J., Burton, J. W. \& Carter, T. E. Phenotypic evaluation of root traits in soybean and applicability to plant breeding. Crop Sci. 36, 456-459 (1996).

87. Pinto, R. S. \& Reynolds, M. P. Common genetic basis for canopy temperature depression under heat and drought stress associated with optimized root distribution in bread wheat. Theor. Appl. Genet. 128, 575-585 (2015).

88. Purcell, L. C. \& Specht, J. E. Physiological traits for ameliorating drought stress. In: Soybeans: Improvement, Production, and Uses. (eds. Boerma, H. R. \& Specht, J. E.) 569-620 (American Society of America, Madison, WI, 2004).

89. Mian, M. A. R. et al. Molecular markers associated with water use efficiency and leaf ash in soybean. Crop Sci. 36, 1252-1257 (1996).

90. Farquhar, G. D., Barbour, M. M. \& Henry, B. K. Interpretation of oxygen isotope composition of leaf material In: Stable isotopes: Integration of Biological, Ecological, and Geochemical Processes. (ed. Griffiths, H.) 27-62 (BIOS Scientific Publishers, Oxford, 1998).

91. Wasson, A. P. et al. Soil coring at multiple field environments can directly quantify variation in deep root traits to select wheat genotypes for breeding. J. Exp. Bot. 65, 6231-6249 (2014).

92. Kaldenhoff, R. \& Fischer, M. Aquaporins in plants. Acta Physiol. 187, 169-176 (2006).

\section{Acknowledgements}

The authors gratefully acknowledge partial funding of this research from the United Soybean Board. Appreciation is extended to Andy King, Marilynn Davies, Jody Hedge, and Scott Hayes for excellent technical support and to Christina Jamieson for secretarial support.

\section{Author contributions}

L.P. conceived of the idea. S.K. and L.P. collected the field data, and S.K. analyzed the data. S.K. wrote the initial manuscript draft, and L.P. revised the manuscript and oversaw the research. Both authors read and approved the final version.

\section{Competing interests}

The author declare no competing interests.

\section{Additional information}

Supplementary information is available for this paper at https://doi.org/10.1038/s41598-020-74614-8.

Correspondence and requests for materials should be addressed to L.C.P. 
Reprints and permissions information is available at www.nature.com/reprints.

Publisher's note Springer Nature remains neutral with regard to jurisdictional claims in published maps and institutional affiliations.

(c) (i) Open Access This article is licensed under a Creative Commons Attribution 4.0 International License, which permits use, sharing, adaptation, distribution and reproduction in any medium or format, as long as you give appropriate credit to the original author(s) and the source, provide a link to the Creative Commons licence, and indicate if changes were made. The images or other third party material in this article are included in the article's Creative Commons licence, unless indicated otherwise in a credit line to the material. If material is not included in the article's Creative Commons licence and your intended use is not permitted by statutory regulation or exceeds the permitted use, you will need to obtain permission directly from the copyright holder. To view a copy of this licence, visit http://creativecommons.org/licenses/by/4.0/.

(C) The Author(s) 2020 